\title{
Use of acoustics in studies of fish reaction to imposed stimuli
}

\author{
E. ONA $\dagger$ and A. K. BELTESTAD $\ddagger$
}

Keywords: Acoustic transducers, fish, biocontrol, behavioural sciences, statistics.

The general distribution pattern of fish in a large pen is described through essentially simultaneous measurements of the integrated echo intensity in each of six separate cells using transducers mounted below the pen. The reaction of fish to various stimuli imposed in one of the cells is quantified by the change in frequency distribution of the echo intensity relative to the undisturbed situation. The experiment was part of a small-scale test of equipment to be used for observations of the attraction-effect of fish to oil-rig structures. The method seems to be suitable both for general fish behaviour studies, including attraction and avoidance effect, and for monitoring feeding systems in aquaculture based on fish conditioning.

\section{Introduction}

It is well known that fish are generally attracted to structures on the seabottom. High concentrations of fish around shipwrecks are commercially exploited by fishermen specializing in this type of fishery. In some areas, artificial reefs are placed on the bottom to increase the fish density (Aska, 1979). Fish are also attracted to the increasing number of oil-rig structures in the North Sea, and significant fish concentrations are found inside the security zones, where they are unexploitable by the fishing fleet.

In a pilot project to study the attraction stimuli to oil rigs, a small-scale test was made to evaluate some of the instrumentation to be used in the main project. One of the methods also seems suitable for general behaviour studies where reactions to imposed stimuli are studied.

The basic idea was to observe the mass transport of fish by six separate echo sounders when the stimuli to be tested are presented in the main lobe of a single transducer. By observing the echo energy statistics for each sounder, the response can be easily quantified.

\section{Materials and methods}

The experiments were made in a sheltered bay near Uggdalseidet on the island of Tysnes, about $50 \mathrm{~km}$ south of Bergen. The fish, saithe (Pollachius virens), was held in a large pen, $90 \mathrm{~m}$ long, $10 \mathrm{~m}$ wide and $7 \mathrm{~m}$ deep, simulating a semi-natural environment. A raft, $8 \times 12 \mathrm{~m}$, with laboratory compartments, was located about

Received 15 January 1987.

This paper was presented at the IFAC Symposium on Automation and Dataprocessing in Aquaculture, Trondheim, Norway, 18-20 August 1986 and also at the 73rd Statutory Meeting of the International Council for the Exploration of the Sea, London 7-16 October 1985.

This paper is reprinted with the permission of IFAC.

$\dagger$ Institute of Marine Research, 5011 Bergen, Norway.

$\ddagger$ Institute of Fishery Technology Research, 5011 Bergen, Norway. 


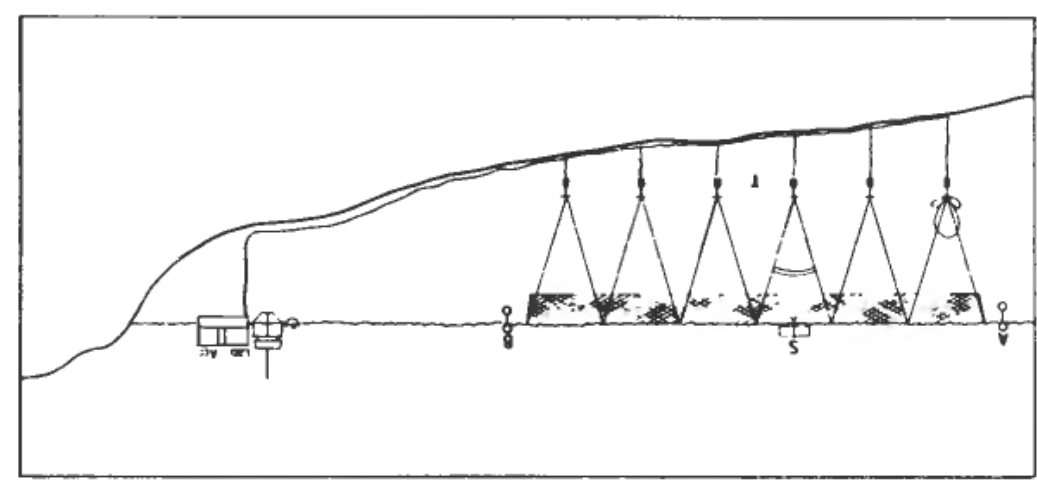

Figure 1. Experimental site with holding pen, transducers (T), stimuli platform (S) and hydrophones (A, B) for acoustical positioning of tagged fish.

$50 \mathrm{~m}$ south of the pen. The small, 42 -foot research vessel 'Fjordfangst' was used for transportation and accommodation for the crew.

Six circular transducers with nominal beamwidth $22^{\circ}$ were mounted in upwardlooking positions below the pen. These were oriented by specially arranged weights and suspension lines to maintain the acoustic axis along the axis of the holding pen, Fig. 1. The transducers were connected to a SIMRAD EY-M $70 \mathrm{kHz}$ echo sounder and QM-II echo integrator via an automatic ping and transducer selector. The basic echo integration method for use with caged fish is described by Johannesson and Mitson (1983).

Prior to the fish measurements, the acoustic system was calibrated using a $60 \mathrm{~mm}$ copper sphere (Foote, 1982; Foote, Knudsen and Vestnes, 1983), and the empty-cage contributions to the echo energy were established.

After transferring about 2000 saithe of nearly uniform length, $31-33 \mathrm{~cm}$, the fish distribution pattern in the pen was measured over a seven-day period. This represented the undisturbed situation, hence defined the baseline for later comparisons with disturbed situations.

All measurements were rendered relative by means of the relations

$$
\begin{array}{r}
A_{i}=\left(U_{i}-E_{i}\right) C_{i} \\
f_{i}=A_{i}\left(\sum_{j=1}^{j=6} A_{j}\right)^{-1}
\end{array}
$$

where

$A_{i}$ corrected and calibrated integrator value in cell no. $\mathrm{i}(\mathrm{mm} / \mathrm{min})$

$U_{i}$ uncalibrated integrator value in cell no. $\mathrm{i}(\mathrm{mm} / \mathrm{min})$

$E_{i}$ empty-cage contribution in cell no. i $(\mathrm{mm} / \mathrm{min})$

$C_{i}$ calibration factor for transducer no. $\mathrm{i}$

$f_{i}$ relative contribution to the total from cell no. i, i.e. relative fish density in cell no. i.

The basic calibration parameters for the echo sounder and integrator, together with the measured empty-cage contribution, are shown in Table 1.

A second system was used to study the overall movements and reactions of single fish carrying acoustic tags. These were positioned within the holding pen by using receiving hydrophones at both ends of the pen, Fig. 1. The positions of the fish were determined by means of a simplified version of the SINTEF pinpoint system 


\begin{tabular}{ccc}
\hline Channel & $\begin{array}{c}\text { Calibration }^{(1)} \\
\text { factor }^{(1)}\end{array}$ & $\begin{array}{c}\text { Empty-cage }^{(2)} \\
\text { contribution } \\
\text { (mm/min) }\end{array}$ \\
\hline I & 0.96 & 14 \\
II & 1.18 & 23 \\
III & 0.95 & 11 \\
IV & 0.91 & 12 \\
V & 1.20 & 11 \\
VI & 0.88 & 10 \\
\hline
\end{tabular}

(1) Estimated from 10-minute integration on a $60 \mathrm{~mm}$ copper sphere, centred on acoustic axis of the transducer in a calibration-rig.

(2) About $5 \%$ of a typical density value.

Table 1. Basic parameters from the calibration of the acoustic system

(Mohus and Holand, 1983). The positions were logged continuously by a computer connected to the positioning system.

Stimuli such as artificial structures with shadowing effects, artificial surface lights, underwater lights with different filters and underwater sound were imposed in one of the cells, or, when preference was being tested, in two non-neighbouring cells. To study the speed of attraction or force of reaction, the increase or decrease of fish density in the stimuli-cell alone was observed.

Hydrography, current speed and direction were continually logged for observation of preference or fish behaviour in relation to these parameters.

\section{Results}

\subsection{General distribution pattern}

A total of about 500 series of measurements of fish distribution pattern in the pen were made during the experiment. A typical series, with two-minute integration by each transducer, is shown in Fig. 2.

Several types of behavioural modes were observed in the undisturbed situation with no artificial stimuli in the pen. Under the typical bright daylight condition, the

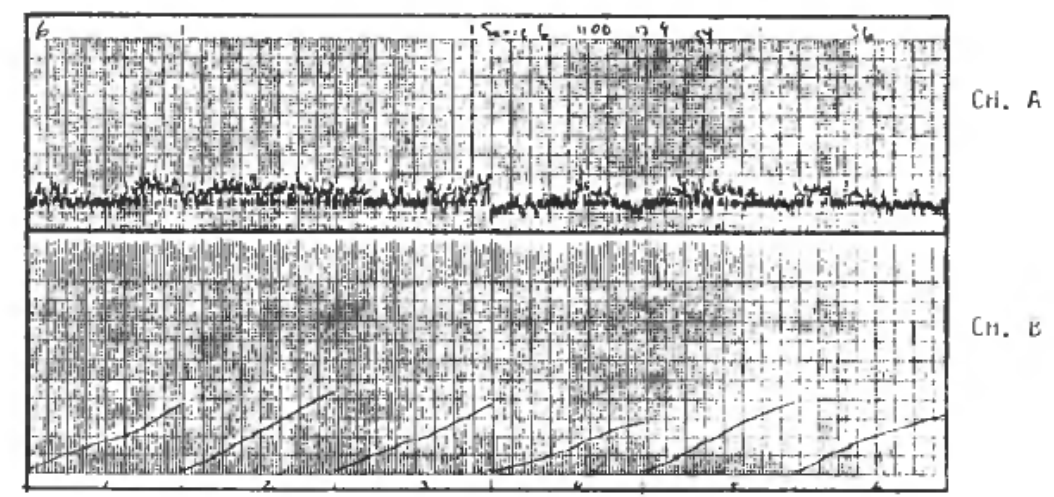

Figure 2. Example from the raw material in which the distribution pattern of fish is nearly ideal. Channel A: Echo energy in each ping. Channel B: Integrated echo energy for two minutes in each cell. 


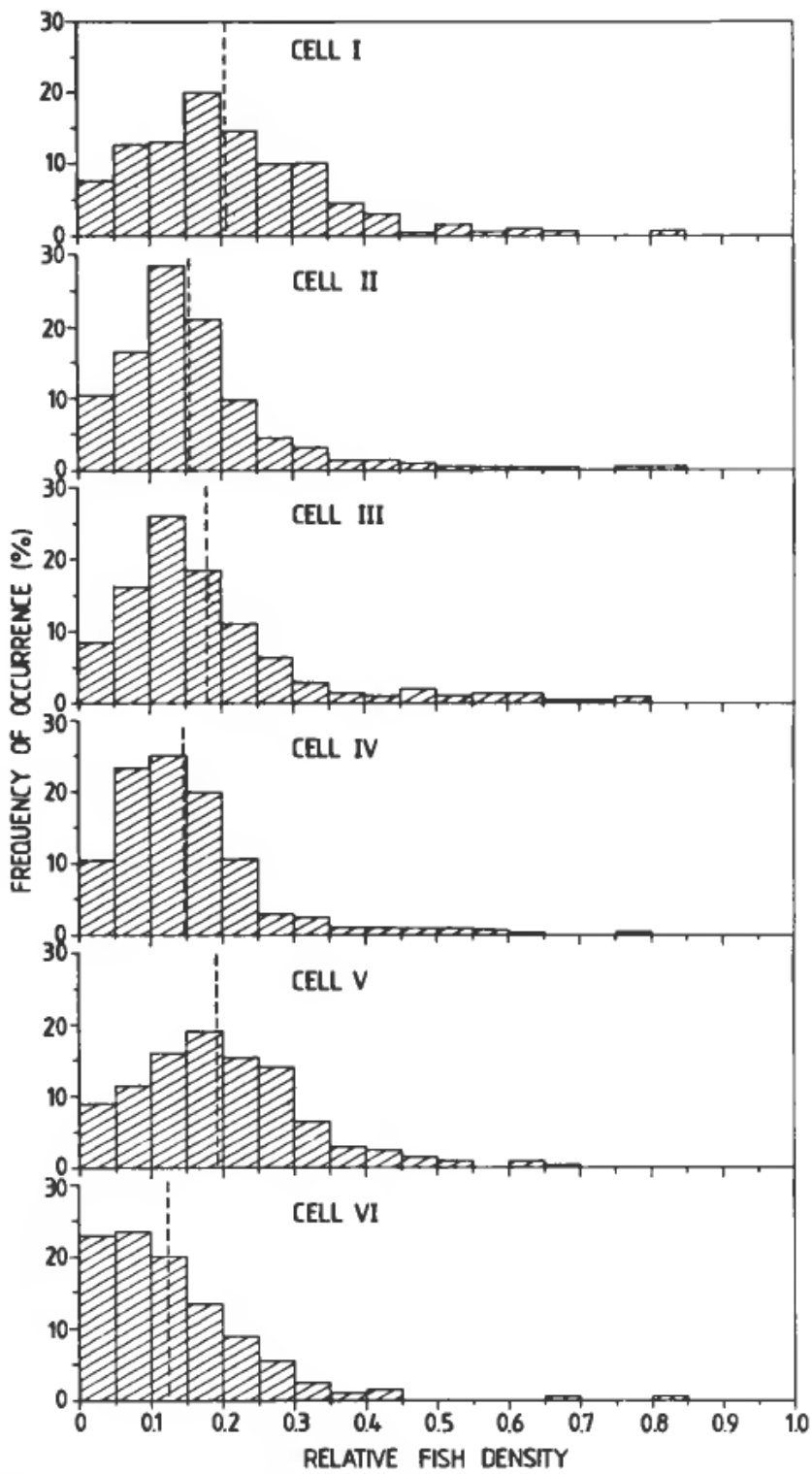

Figure 3. Observed fish densities in each cell over a three-week period, representing 359 measurement series on undisturbed fish.

fish were evenly distributed near the bottom of the pen, or were schooling slowly back and forth in the deeper part of the pen. In the evening, heavy feeding activity was observed during most of the experimental period, with the fish evenly distributed horizontally near the surface. The fish also showed a preference for the cell most exposed to tidal current in the fjord.

The natural variability of distributions within the pen is seen from the frequency of fish densities in each cell, Fig. 3. The central part of each distribution reflects a stable, nearly ideal distribution pattern, while the tails, where up to $85 \%$ of the fish are located within a single cell, are results of schooling activity, only rarely seen in the pen. 


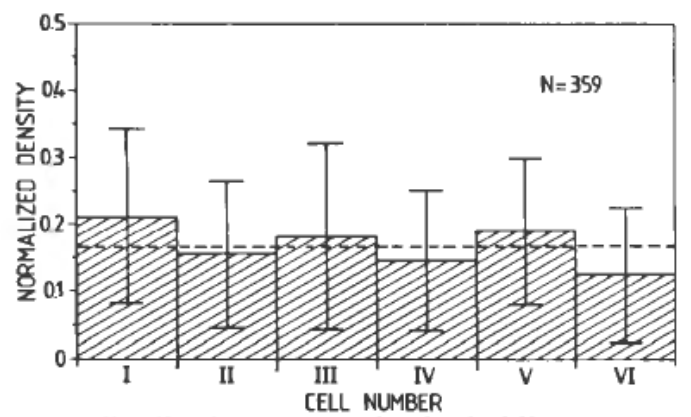

Figure 4. Observed mean distribution pattern in the holding pen over a three-week period. Standard deviation, together with the ideal pattern, is shown.

A general description of the undisturbed situation is shown in Fig. 4. The diagram represents the distribution of fish in the pen over a three-week period. The stippled line indicates the ideal distribution pattern, with equal amounts of fish in each cell. Using this distribution as a model in a Chi-square test, the observed distribution pattern is not significantly different from the ideal $(p>0.25)$. A certain preference for the cell most exposed to the weak tidal current in the fjord is seen. The cell located in the inner part of the bay is consequently less exposed to the current, and the fish density is also slightly lower.

The individually tagged saithe seemed to prefer the central part of the pen, almost totally avoiding the inner part of the bay, cell no. VI, Fig. 5.

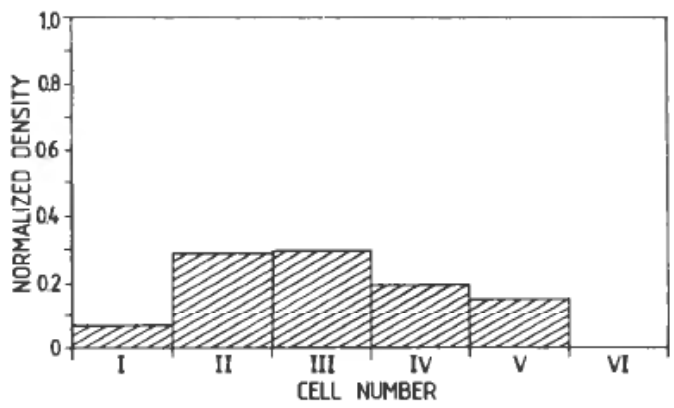

Figure 5. Distribution pattern of the individually tagged fish from the positioning system over the same three-week period.

\subsection{Response to stimuli}

The stimuli to be tested were presented in one of the four central cells, usually nos. III or V, or in both when preference was being tested. To quantify the reaction, a series of measurements were made before and after imposition of the stimuli. A typical example, that of attraction to white underwater light, $1000 \mathrm{~W}$, is shown in Fig. 6. More than $70 \%$ of the fish were attracted to the light-cell, and strong feeding activity on naturally occurring organisms was observed. The distribution patterns before and after use of the light were nearly ideal. The attraction to the same light mounted above the surface was also strong but not comparable to underwater light, Fig. 7. The attraction range also seems to be significantly reduced.

When testing preference, cell nos. III and V were used simultaneously, and preference to either of the stimuli-sources was then observed as a gradual increase in 


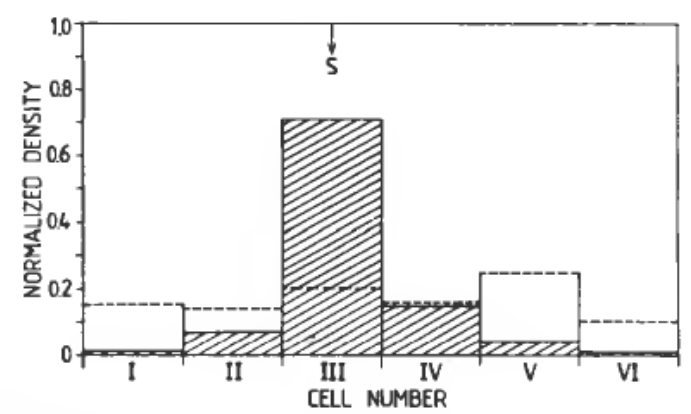

Figure 6, Observed reaction to white underwater light $(1000 \mathrm{~W})$ in cell no. III. Mean distribution pattern before and after the stimulus is shown by the stippled lines.

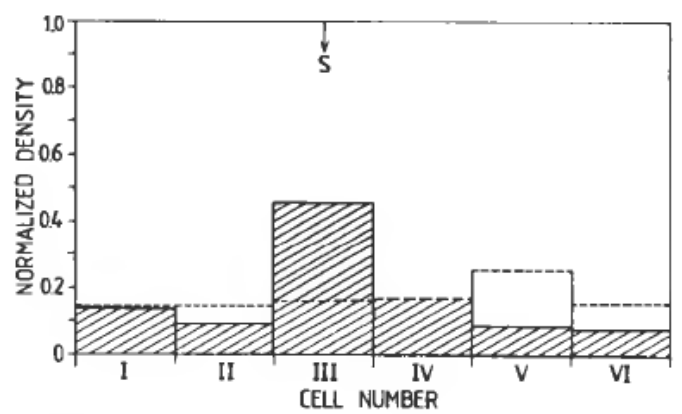

Figure 7. Reaction to white surface light $(1000 \mathrm{~W})$ in cell no. III.

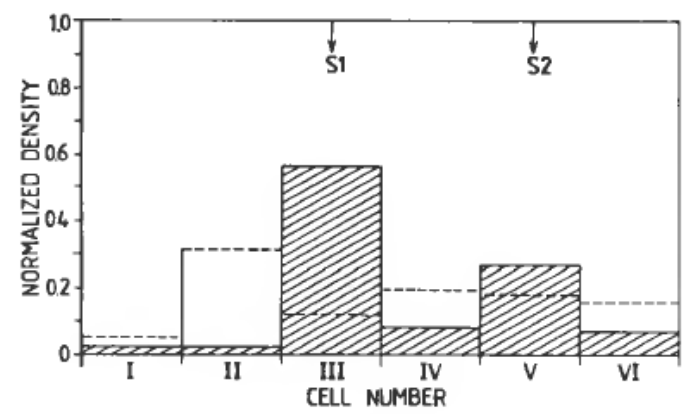

Figure 8. Example of reaction when preference to filtered light was tested. S1-blue underwater light, S2-red underwater light, both $500 \mathrm{~W}$.

echo energy in one of the cells, with a comparable reduction in the other. A significant increase of the fish density to comparable levels in the two cells was normally observed during the first minutes in such a test. Before reaching a stable distribution pattern, however, a certain portion of the fish in one of the cells would move to the preferred cell. Figure 8 shows a stable pattern 30 minutes after introducing a blue $500 \mathrm{~W}$ underwater lamp in cell no. III and a red $500 \mathrm{~W}$ underwater lamp in cell no. $V$.

\subsection{Speed of reaction}

The reaction speed could be studied by observing the change in echo energy in the stimulus cell per unit time. An example of the speed of attraction to a low- 


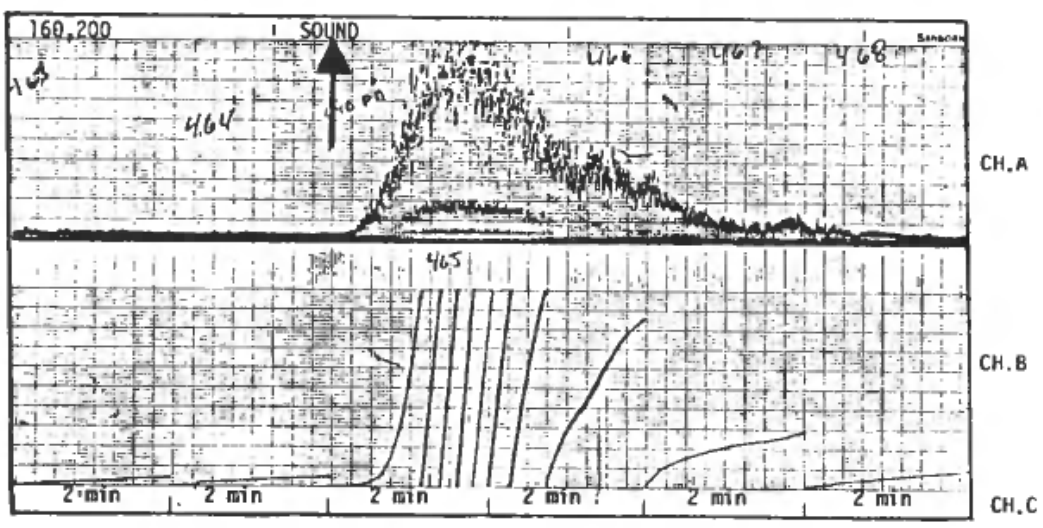

Figure 9. Example of the attraction to a pulsed underwater sound stimulus $(160 \mathrm{~Hz}$, $200 \mathrm{~ms}$ ), observed using only the transducer in the stimulus cell. Time scale is $2 \mathrm{~min}$. between the vertical bars in $\mathrm{CH}$. C. Sound source activation is indicated by the arrow.

frequency, $160 \mathrm{~Hz}$, pulsed underwater sound source is illustrated in Fig. 9. There was a very rapid increase in fish density within the cell during the first two minutes after the sound signal was started, but as no additional stimulus was given, no further interest was displayed, and the fish density decreased gradually.

Similar observations were made with several stimuli, the exception being that of the light stimuli, where an increased fish density was maintained within the cell over long periods. The naturally occurring food organisms available, perhaps also attracted to the illuminated cell, made this more a conditioned reflex.

\section{Discussion}

The experiment clearly shows the potential of the acoustic method in studies of fish reaction to imposed stimuli. The relatively strong stimuli in this investigation were used more to demonstrate and evaluate the multi-element integration method than to investigate attraction to stimuli, as in Protasov (1970).

The strength of the method lies in the possibility of directly quantifying the reactions to a stimulus. Using the additional information in a series like that of Fig. 9 , it should also be possible to quantify the reaction strength.

Further analysis of the data will include a simplified model for mass transport of fish into or out of the stimulus area, described through equations of the form:

$$
\frac{d N}{d t}=\beta\left(N_{t}-N_{0}\right) \exp (-\alpha t)
$$

where

$N$ Instantaneous number of fish in the stimulus cell.

$N_{t}$ Total number of fish in the pen.

$N_{\mathrm{o}}$ Number of fish within the stimulus-cell before stimuli.

$\alpha, \beta$ Negatives of rate parameters.

This will hopefully describe the transport rate of fish into the stimulus cell. The rate parameters will then constitute estimates of reaction strength to the stimuli. For 
more diffusive stimuli, like bait or chemicals simulating bait, the reaction distance should also be included.

The promising results from the pilot project have instigated plans for a more sophisticated system, in which the echo energy statistics can be monitored in real time.

\section{Conclusions}

The acoustic method can be used to quantify fish reactions to presented stimuli. The method can be used both in semi-natural environments and in the sea. The attraction effects of stimuli based on light and sound have been demonstrated using this technique. The attraction force may be further quantified from the data.

Significant differences in long-term fish distribution patterns of undisturbed fish involving all fish and individually tagged fish is seen. This may indicate that the process of tagging, or the tag itself, introduces a behavioural difference.

\section{ACKNOWLEDGMENT}

This paper was first presented at the 73rd Statutory Meeting of the International Council for the Exploration of the Sea, London 7-16 October 1985.

\section{REFERENCES}

AskA, D. Y. (1979). Artificial reefs. In D. Y. Aska (Ed.), Proceedings of the conference held in Sept. 1979, Paytona Beach Florida, Florida: Sea Grant College, 1981. (Sea Grant Programme report 41).

FooTE, K. G. (1982). Optimizing copper spheres for precision calibration of hydroacoustic equipment. J. Acoust. Soc. Am., 71, 742-747.

Foote, K. G., KNUdSEN, H. P. A., and Vestnes, G. (1983). Standard calibration of echo sounders and integrator with optimal copper spheres. FiskDir. Skr. Ser. HavUnders., $17,335-346$.

JohanNesson, K. A., and Mitson, R. B. (1983). Fisheries acoustics. A practical manual for aquatic biomass estimation. F.A.O. Fish. tech. Pap., (240), 249 pp.

MoHus, I., and Holand, B. (1983). Fish telemetry manual. SINTEF report STF48 A83040 Dec. 1983,97 pp.

Protasov, U. R. (1970). Vision and near orientation of fishes. Transl. From Russian, Israel Program for Scientific translations, John Wiley and Sons, Jerusalem 1970, 175 pp. 